\title{
Spatial distribution of Radium in coastal marine waters of Tamil Nadu
}

\author{
S.K. Jha ${ }^{1}$, P. Hemalatha ${ }^{2}$, S. Rajaram ${ }^{2}$ and V.D. Puranik ${ }^{1}$ \\ ${ }^{1}$ Environmental Assessment Division \\ ${ }^{2}$ Health Physics Division Bhabha Atomic Research Centre, Mumbai-400 085, India \\ e-mail: skjha@barc.gov.in
}

\begin{abstract}
An investigation on the distribution of Radium activity levels in the entire south-eastern coast of Tamilnadu, India, from Chennai to Kanyakumari was carried out. Insitu preconcentration technique was adopted by passing 1000 liters of seawater through $\mathrm{MnO}_{2}$ impregnated cartridge filters at all the locations. In the coastal waters, ${ }^{226} \mathrm{Ra}$ and ${ }^{228} \mathrm{Ra}$ concentration was observed to be in the range of 1 to $1.81 \mathrm{mBq} / \mathrm{l}$ and 3.1 to $7.5 \mathrm{mBq} / \mathrm{l}$ respectively with an average of 1.52 and $4.53 \mathrm{mBq} / \mathrm{l}$ respectively, while the sediment samples showed ${ }^{226} \mathrm{Ra}$ activity levels from 8.1 to $129.0 \mathrm{~Bq} / \mathrm{kg}$ and ${ }^{228} \mathrm{Ra}$ varied from 14.7 to $430.01 \mathrm{~Bq} / \mathrm{kg}$. The concentration of ${ }^{228} \mathrm{Ra}$ was observed to be more than ${ }^{226} \mathrm{Ra}$ in all the locations. The activity ratio of ${ }^{228} \mathrm{Ra} /$ ${ }^{226} \mathrm{Ra}$ in the Bay of Bengal showed a ratio varying from 0.8 to 2.4 with a mean of 2.1 . In the present study, activity ratio varies from 1.9 to 2.4 at Karaikkal. But the regions of Rameswaram and Kanyakumari which comprises the high natural background region reflects different ratio varying from 3.5 to 6.9 , reflecting different sources of weathered material for ${ }^{228} \mathrm{Ra}$. The findings supported the fact that the area also comes under natural high radiation background at the south west of Indian peninsula due to the presence of heavy mineral containing monazite. The spatial distribution of the activity with respect to location is discussed in the paper. The radioactive database obtained represents reference values for coastal environment of Tamil Nadu.
\end{abstract}

\section{INTRODUCTION}

Three Radium isotopes from the natural Uranium and Thorium series viz. $\mathrm{Ra}^{228}, \mathrm{Ra}^{226}$ and $\mathrm{Ra}^{224}$ are important radionuclides of concern which gives out Radon by alpha decay and has gamma and beta activities. Due to its long half-life (1600y) and its radiological effects, Radium-226 and its daughter products are considered as the radionuclide responsible for internal dose received by humans from naturally occurring radionuclides $[1,2]$. Radium enters the ocean waters through diffusion across the sediment-water interface where a large concentration gradient of ${ }^{226} \mathrm{Ra}$ exists due to the deposition of particle-borne ${ }^{230} \mathrm{Th}$. Both ${ }^{226} \mathrm{Ra}$ and ${ }^{228} \mathrm{Ra}$ are soluble nuclides but have a strongly particle reactive progenitor such as ${ }^{230} \mathrm{Th}$ and ${ }^{232} \mathrm{Th}$ respectively. However Th gets enriched in sediments while radium tends to stay in solution and thus Radium produced through decay in the sediment escapes back into the water column. Thus the distribution of Ra isotopes in the water column depends on their respective half-lives as well as the distribution of their parent nuclides in the sediments. These properties can afford useful insights into geochemical processes. The sediment accumulates the radionuclides as a result of scavenging and settling process in the water column thus playing an important role in the cycling of radionuclides. A well known high-level natural background radiation region was observed in the southern coast of India which is due to pockets of monazite bearing beach sands [3, 4]. In the recent years, there has also been an increased recognition of the radiological significance of non nuclear process of natural radioactivity in particular ${ }^{226} \mathrm{Ra}^{228}{ }^{2 a},{ }^{222} \mathrm{Rn},{ }^{210} \mathrm{Po}$ and ${ }^{210} \mathrm{~Pb}$ produced , for example by Phosphate processing plants, offshore oil and gas installations and ceramic industries etc [9]. Keeping 


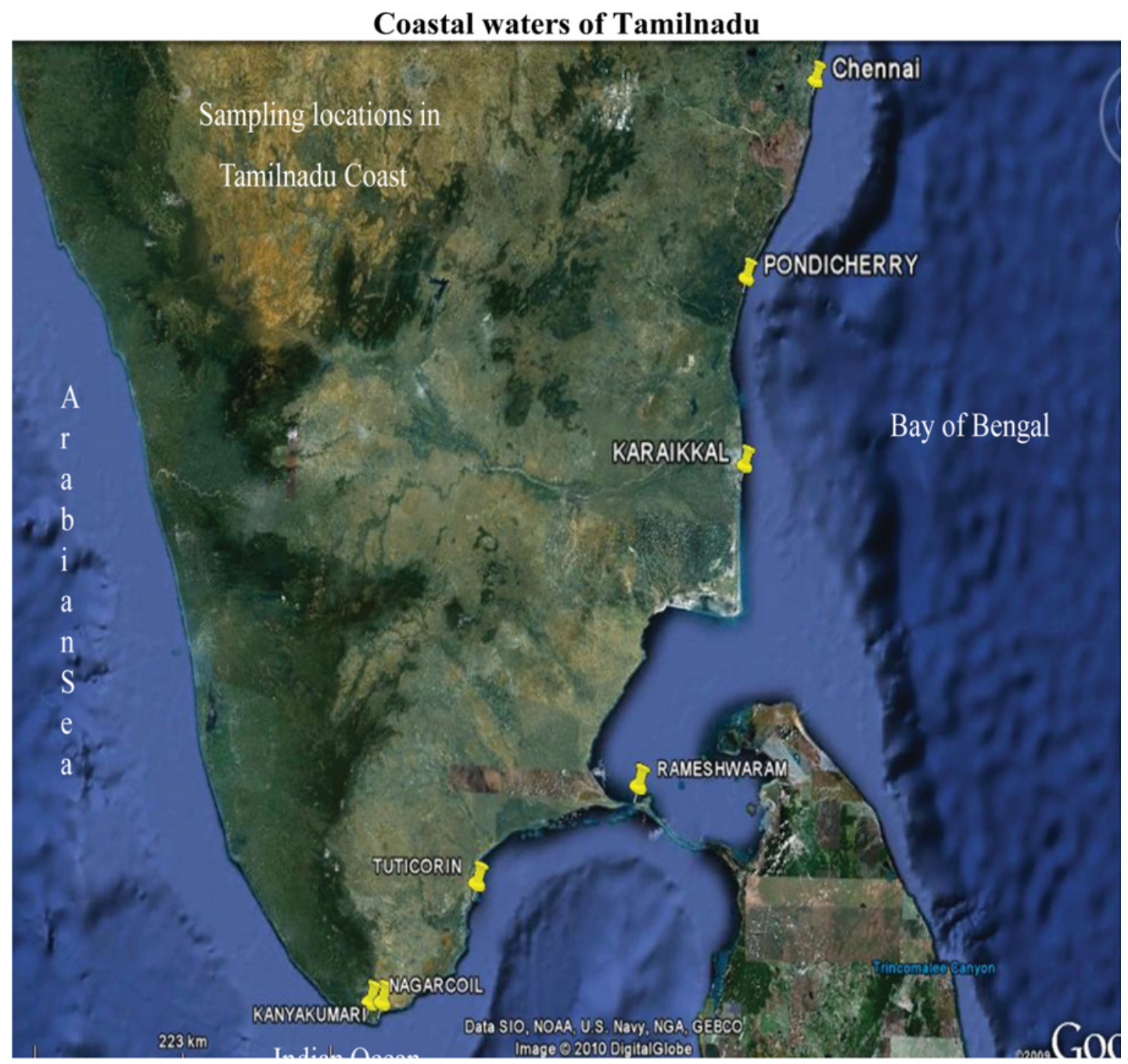

Figure 1. Sampling locations for Radium measurement in the Coastal waters of Tamilnadu.

this in mind, present investigation is carried out to generate site specific values of Radium which will serve as reference values for eastern coastal environment of India.

\section{STUDY AREA AND THEIR IMPORTANCE}

The coastal line of Tamilnadu stretches about $900 \mathrm{~km}$ from Chennai to Kanyakumari with a unique topography of Gulf of Mannar and Kanyakumari facing three oceans. The present study area in the eastern coastal line of Bay of Bengal covers latitudinal and longitudinal extensions of $12^{\circ} 58^{\prime} 03.8^{\prime}$ 'N to $08^{\circ} 05^{\prime} 18^{\prime \prime} \mathrm{N}$ and $80^{\circ} 16^{\prime} 05.1^{\prime \prime} \mathrm{E}$ to $77^{\circ} 29^{\prime}$ 9.3”'E (fig 1). Seven offshore locations were selected such as Chennai, Pondicherry, Karaikkal, Rameshwaram, Tuticorin, Nagercoil and Kanyakumari for sampling. Using a boat, about 100 meters away from the shore, sampling was carried out in the sea. The coastline in this region is largely submerged in nature and offshore stalks, long beaches, estuaries, lagoons, spits, sand and bars are characteristic of this coast. The sand ridges, expensive lagoons and barrier island are indicative of a dynamic coast with transgression and regression in geological past. The 
extent of vertical run-up of sea water depends on geographical location, bathymetry, and beach. Climate of this area is characterized by an oppressive hot summer, humidity in atmosphere nearly through out the year and reasonably good seasonal rainfall. Each location is chosen based on geographical importance to predict the distribution of natural radioactivity. The Marina Beach ,Chennai, on this coastline is one of the longest beaches in the world stretching to a length of about $12 \mathrm{~km}$ along the shoreline of the city. Pondicherry; due to its geographical location in Bay of Bengal, experiences 2 to 3 cyclones annually and its coast line faces severe erosion. The $3^{\text {rd }}$ location Karaikkal is in the middle of Tamil Nadu coast, midway between the two deepwater ports of Chennai and Tuticorin. It is a small coastal enclave of territory. Karaikal faced its worst tragedy when Tsunami hit the coast. Karaikkal port is a new deep sea water port and provides an alternative to the Chennai and Tuticorin ports. The $4^{\text {th }}$ location Rameswaram is located on an island separated from mainland by the Pamban channel and is less than 40 kilometers from the Jaffna Peninsula. It is situated in the Gulf of Mannar at the very tip of the Indian peninsula. The $5^{\text {th }}$ location Tuticorin coast has a major port and it is a rapidly developing area. Due to the accelerated development activities, the coastal area experiences significant changes. Tuticorin serves as a centre of maritime trade and pearl fishery. The $6^{\text {th }}$ location Nagarcoil coastline is rocky in several places and sandy near the town. The sea around is rich in common varieties of fish like tuna, sardines, etc. The $7^{\text {th }}$ location Kanyakumari coastal ecosystem comprises $68 \mathrm{Km}$ in length and is studded with coastal fishing villages. Since this District is situated at the extreme south of the Indian subcontinent, the coastline is formed nearly by three seas, namely, Arabian Sea, Indian Ocean and Bay of Bengal. But the main part of the coast faces the Arabian Sea. The coastal landscape of Kanyakumari District is mainly composed of beach ridges of rocky, sandy and swampy nature in the estuarine regions.

\section{METHODOLOGY}

Several methods are available for the determination of radium isotopes which include the conventional co-precipitation of radium with $\mathrm{Pb}, \mathrm{Ba}$ Sulphate followed by measurement by gamma-ray spectroscopy ,beta counting, ${ }^{222} \mathrm{Rn}$ emanation, liquid scintillation counting, or alpha spectrometry [5, 6]. These methods involve different chemical reactions and is relatively complex and time consuming. For low level activities, collecting hundreds of liters of water from different locations, processing, handling and measurement of the low activity becomes strenuous and cumbersome. To overcome this difficult task and to measure the low level activity in much more easier and efficient way, an insitu preconcentration of the radionuclide on the $\mathrm{MnO}_{2}$ coated filter cartridges was adapted. For pre-concentration of radium in sea water, one micron pore size Polypropylene cartridges were coated with saturated solution of $\mathrm{KMnO}_{4}$ prepared in de-ionized water with continuous heating, maintaining temperature at $50^{\circ} \mathrm{C}$. The cartridges were prepared in batches of two to estimate collection efficiency under similar conditions. Based on constraints experienced in the field conditions, the system has built-in facilities for silt removal, double exchanger cartridge system for efficiency and less sampling error in the measurement. In all locations 1000 liters of seawater was passed through the cartridges with a flow rate of 10 lit. per minute. The experiments were carried out in triplicates in all locations. Finally the cartridges were dismantled from the set up, $\mathrm{MnO}_{2}$ coated cartridges were removed and sealed in polythene covers. In the laboratory, the cartridges were ashed at $300^{\circ} \mathrm{C}$ and taken in a standardized geometry for Gamma counting. The samples were filled in plastic boxes, sealed and the activities were measured using a high resolution, 50\% relative efficiency p-type Co-axial HPGe detector, (Eurisys Measures) coupled to a $8 \mathrm{k}$ multichannel Analyser for a counting period of 60000 seconds. The detector was housed inside a lead shield to reduce background. Energy and Efficiency calibration were done with three IAEA Standard reference material; a Standard soil of known activity, Uranium ore sample RGU1 and Thorium ore sample RGTh-1 in similar geometry. ${ }^{226} \mathrm{Ra}$ was estimated from the gamma line of ${ }^{214} \mathrm{Bi}$ at $1.765 \mathrm{MeV}$ with a gamma abundance of $15.4 \%$ and ${ }^{226} \mathrm{Ra}$ was estimated from the ${ }^{208} \mathrm{Tl}$ peak at $2.426 \mathrm{MeV}$. The activity concentration of the radionuclide was determined using the total net count under the selected 


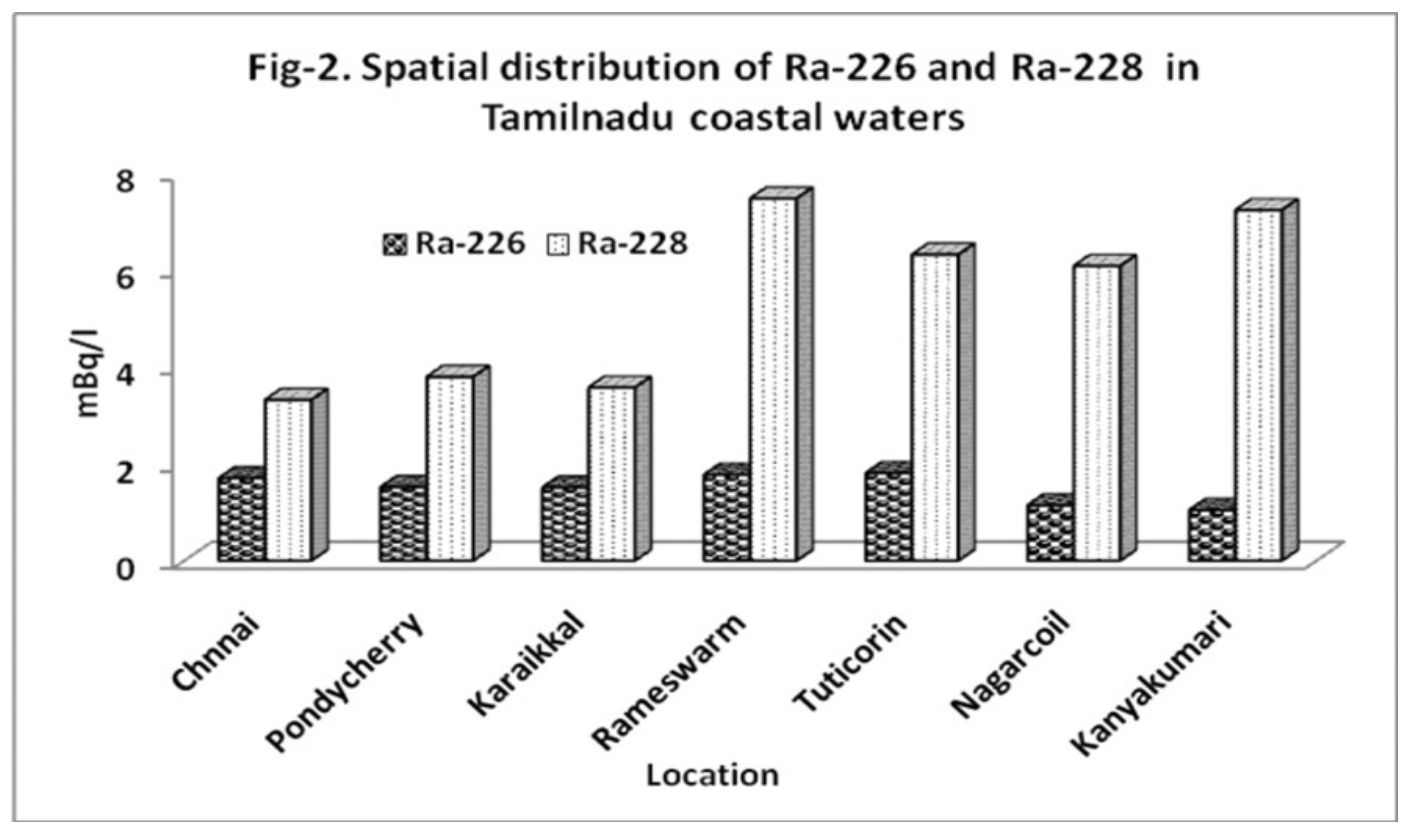

Figure 2. Spatial distribution of Ra-226 and Ra-228 in Tamilnadu Coastal waters.

photopeak after subtracting the background counts, and applying the appropriate factors such as photo peak efficiency, gamma intensity of the radionuclide and weight/volume of the sample.

\section{RESULTS AND DISCUSSION}

Fig 1 shows the sampling locations in the coastal area of Tamil Nadu. The activity concentration of ${ }^{226} \mathrm{Ra}$ and ${ }^{228} \mathrm{Ra}$ in the Tamilnadu coastal waters obtained from different locations is given in Fig 2 . The concentration of ${ }^{226} \mathrm{Ra}$ in the seawaters was found lesser than the concentration of ${ }^{228} \mathrm{Ra}$ in all locations. ${ }^{226} \mathrm{Ra}$ concentration was in the range of 1.05 to $1.81 \mathrm{mBq} / \mathrm{L}$ in the coastal waters showing slightly higher values at Tuticorin, Chennai and Rameswaram. In figure 2, distinct trends were observed in the concentration of ${ }^{228} \mathrm{Ra}$ with higher values from Rameshwaram to Kanyakumari waters in the range of 6.07 to $7.47 \mathrm{mBq} / \mathrm{l}$ while in the northern region of the coastal waters at Chennai to Karaikkal, it ranged from 3.3 to $3.8 \mathrm{mBq} / \mathrm{l}$. Sediment activities from this coastal line also showed higher concentration of ${ }^{228} \mathrm{Ra}$. At Rameshwaram and Karaikkal, activity of ${ }^{228} \mathrm{Ra}$ was observed as 178.93 and $143.29 \mathrm{~Bq} / \mathrm{kg}$ respectively, while the highest value of $430.09 \mathrm{~Bq} / \mathrm{kg}$ was observed at Kanyakumari. ${ }^{226} \mathrm{Ra}$ in these sediments was in the range of 8.08 to $129.02 \mathrm{~Bq} / \mathrm{kg}$ showing higher concentrations at Karaikkal, Rameshwaram and kanyakumari. Out of the seven locations, Kanyakumari showed higher concentration of both radium isotopes. The major source of ${ }^{226} \mathrm{Ra}$ is the production from the ${ }^{230} \mathrm{Th}$ in the upper layer of sediment. The sedimentary flux in the coastal region of Karaikkal ,Chennai and Pondicherry is influenced by Periyar river.

The activity ratio of ${ }^{228} \mathrm{Ra} /{ }^{226} \mathrm{Ra}$ at the three locations in the Bay of Bengal varied from from 1.9 to 2.4 with a mean of 2.1. In the south west region locations; Rameswaram and Kanyakumari represents a high natural radioactive background region, an elevated ${ }^{228} \mathrm{Ra} /{ }^{226} \mathrm{Ra}$ ratio of 3.5 to 6.9 reflects distinguished source of weathered material for ${ }^{228} \mathrm{Ra}$. The mountain range of the western ghats with average altitude of $1000-1300 \mathrm{~m}$ is the prominent landform in the hinterland of the coastal region from Rameswaram to Kanyakumari. This part of Tamilnadu region receives highest rainfall during tropical monsoon. This is responsible for deposit of sand containing monazite along the coast of southern most 


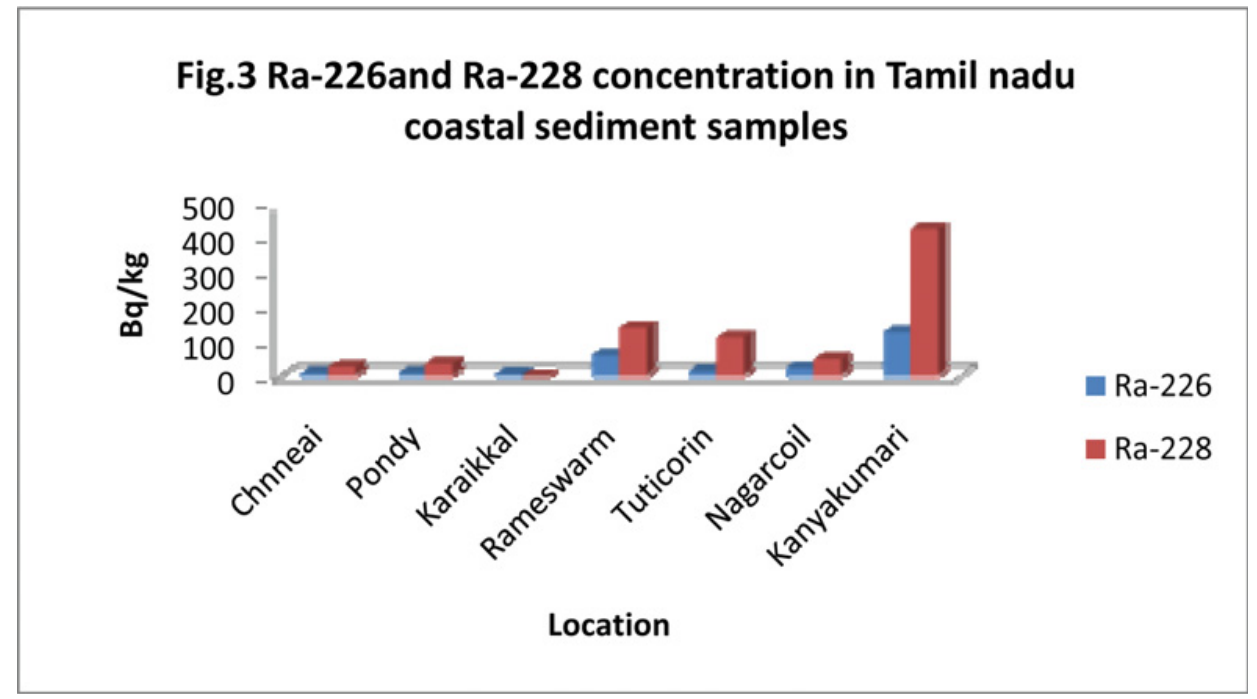

Figure 3. Ra-226 and Ra-228 concentration in Tamil nadu Coastal sediment samples.

part of Tamilnadu. The findings supported the fact that the area also comes under natural high radiation background at the south west of Indian peninsula due to the presence of heavy mineral containing monazite $[7,8]$.

Willard S. Moore, 1977 [9] has measured the ${ }^{226} \mathrm{Ra}$ and ${ }^{228} \mathrm{Ra}$ in the surface water in the Bay of Bengal and reported a ratio of two in the area by mouth of Ganga-Bramhaputra river. The desorption of radium isotopes from sediment of Ganga-Bramhaputra river is the major point source whose ratio varies from 1.8 to 2.4 with the mean of 2.1. Another study in the bay of Bengal near Chittagaon area showed ${ }^{228} \mathrm{Ra} /{ }^{226} \mathrm{Ra}$ ratio of 0.3 that was observed in the sea water indicating a different source for radium in the area which was reported by Satyajit Ghose et.al., 2000 [10].

In our studies at three locations, the ratio of ${ }^{228} \mathrm{Ra} /{ }^{226} \mathrm{Ra}$ varies from 1.7 to 2.4 . But as we move towards the southern part a marked changed in the ratio of ${ }^{228} \mathrm{Ra} /{ }^{226} \mathrm{Ra}$ from 2.4 to 6 was observed.

\section{CONCLUSION}

Present study gives a site specific distribution of ${ }^{226} \mathrm{Ra}$ and ${ }^{228} \mathrm{Ra}$ levels in the Indian eastern coastal waters of Tamilnadu, by insitu preconcentration technique. ${ }^{226} \mathrm{Ra}$ concentration was observed to be in the range of 1.05 to $1.81 \mathrm{mBq} / \mathrm{L}$ with an average of 1.52 while ${ }^{228} \mathrm{Ra}$ was in the range of 3.1 to $7.5 \mathrm{~Bq} / 1$ with an average of $4.53 \mathrm{mBq} / \mathrm{L}$. Due to the geographical and physico chemical nature of the coastal line, the values were observed to be higher in the coastal environment of Kanyakumari, Rameshwaram and karaikkal. The enhanced value of ${ }^{228} \mathrm{Ra}$ in the shallow coastal region is characteristic of the origin of the source. In general, higher ${ }^{228} \mathrm{Ra}$ levels were observed in the coastal waters and sand compared to ${ }^{226} \mathrm{Ra}$, which is attributed to the production of the radionuclide from the Thorium rich sediment. The higher activity ratio of ${ }^{228} \mathrm{Ra} /{ }^{226} \mathrm{Ra}$ might imply that radium isotopes are derived from weathered materials coming from different sources in the two regions. These data represents reference values for Indian coastal regions and will be used to estimate radionuclide inventory in Indian marine environment, particularly at the East Coast of the country.

\section{Acknowledgments}

The authors are grateful to Dr. A. K. Ghosh, Director, HS\&E Group, BARC, Dr. D.N.Sharma, AD, H, S\&E group, BARC Mumbai for their keen interest and constant encouragement. 


\section{References}

[1] T. Kovacs, E. Bodrogi, J. Somlai, V. Jobbágy, G. Patak, Cs. Nemeth-2003 J. Radioanal. Nucl. Chem. Vol. 258, No. 1 (2003) 191.194

[2] Malanca. A, Gaidolfi. L, Pessina.V, Dallara.G, 1996 J. Environ. Radioact. 30, 55-67

[3] UNSCEAR, 2000. Sources and effects of ionizing radiation. United Nations Scientific Committee on the Effects of Atomic Radiation, United Nations, New York.

[4] Radhakrishna, A.P., Somashekarappa, H.M., Narayana. Y., Siddappa. K., 1993. A new natural background radiation area on the southwest coast of India. Health Physics. 65, 390-395.

[5] Guogang Jia, G. Torri, P. Innocenzi, R. Ocone, A. Di Lullo J. Radioanal and Nucr Chem, Vol. 267, No.3 (2006) 505-514

[6] J. Eikenberg, A. Tricca, G. Vezzu, S. Bajo, M. Ruethi and H. Surbeck, 2001 J. Environ. Radioact., 54(1), 109-131

[7] G.K. Raju, J. Mathai, G.R.R. Kumar, N.G.K. Nair, Proc. Indian Acad. Sci.(Earth and Planetary Sci.) 95 (3) (1986) 397-407.)

[8] Kannan, V., Rajan, M.P., Iyengar, M.A.R., Ramesh, R., 2002. Appl. Radiat. Isot.57, pp109-119

[9] Williard S. Moore. High flux of radium and barium from the mouth of the Ganges-Brahmaputra river during low river discharge suggest a large ground water source . Earth and Planetary Science letters 150 (1977) 141-150

[10] Satyajit Ghose et. al. 2000 . Concentrations of ${ }^{222} \mathrm{Rn},{ }^{226} \mathrm{Ra}$ and ${ }^{228} \mathrm{Ra}$ in surface sea water of the Bay of Bengal Journal of Environmental Radioactivity 47 (2000) 291-300. 